\title{
Tamsulosin alters levofloxacin pharmacokinetics in prostates derived from rats with acute bacterial prostatitis
}

\author{
Guo-Dong Qin ${ }^{1 *}$, Ming-Zhao Xiao ${ }^{1 *}$, Yuan-Da Zhou ${ }^{2}$, Jing Yang ${ }^{3}$, Hai-Xia He ${ }^{2}$, Yue He ${ }^{1}$ and Yang Zeng ${ }^{1}$
}

The combination of levofloxacin and $\alpha_{1}$ adrenergic antagonist treatment is the current preferred choice for both bacterial and non-bacterial prostatitis. The aim of this study is to explore the influence of $\alpha_{1}$ adrenergic antagonists on the pharmacokinetics of levofloxacin using rat models with acute bacterial prostatitis (ABP) induced by direct injection with Escherichia coli (ATCC25922). A total of 96 model rats were randomly assigned into two groups: the experimental group (treated with both tamsulosin and levofloxacin, $n=48$ ) and the control group (treated with levofloxacin and solvents, $n=48$ ). Six rats from each group were euthanized to collect blood, liver, kidney and prostate samples at the time points of $0.125,0.25,0.5,1,2,4,8$ and $12 \mathrm{~h}$ after drug administration. The levofloxacin concentrations were detected by high performance liquid chromatography (HPLC), and the pharmacokinetic parameters were calculated using the $3 \mathrm{p} 97$ software program. There were no obvious differences $(P>0.05)$ between the experimental and control groups in the major pharmacokinetic parameters of levofloxacin, including the halftime $\left(t_{1 / 2}\right)$, time to peak $\left(t_{\text {peak }}\right)$, clearance rate $(C L)$, maximum concentration $\left(C_{\max }\right)$ and area under the curve $\left(A \cup C_{0 \sim 12}\right)$, in the plasma or in the hepatic and kidney tissues of the model rats. However, in the prostatic tissues, tamsulosin increased the $C_{\max }$, prolonged the $t_{1 / 2}$ and decreased the CL of levofloxacin $(\boldsymbol{P}<0.05)$. These results indicate that tamsulosin may enhance the effect of levofloxacin in the treatment of bacterial prostatitis without changing the drug concentration in the liver and kidney.

Asian Journal of Andrology (2013) 15, 254-260; doi:10.1038/aja.2012.134; published online 28 January 2013

Keywords: $\alpha_{1}$ adrenergic antagonist; antibiotic pharmacokinetics; prostatitis; rats

\section{INTRODUCTION}

Prostatitis is the most common urological disease diagnosed in men. It has a complex aetiology and a low recovery rate with frequent recurrences, which leads to an impaired quality of life. ${ }^{1-4}$ The prostatic capsule forms a barrier against changes in $\mathrm{pH}$ value after infection, and its calcification limits the ability of medication to achieve a sufficient concentration in the prostate, resulting in a poor clinical efficacy against infectious diseases. Fluoroquinolones with high bioavailability, especially levofloxacin, which has a bioavailability up to $99 \%$, can be absorbed quickly and demonstrate good tissue permeability, leading to high drug concentrations in the plasma and prostate. Thus, fluoroquinolones are the preferred agents for treating bacterial causes of prostatitis and have even demonstrated efficacy in some cases of chronic prostatitis when an organism has not been identified..$^{5-8} \alpha$-adrenergic antagonists can selectively block the excitability of smooth muscle in the urethra, bladder neck and prostate, which contributes to a relaxation of prostate tissue, a reduction of urethral resistance and easing of the functional urethral obstruction, thus improving patient scores for pain, urinary symptoms and quality of life.

Many studies have shown that combination therapy was significantly more effective than monotherapy; therefore, two agents, such as antibiotics plus $\alpha_{1}$ adrenergic antagonists, may have a synergetic effect on the treatment of chronic bacterial and non-bacterial prostatitis. ${ }^{9-11}$ Tamsulosin, a new-generation, highly selective $\alpha_{1 \mathrm{~A}}$ adrenergic antagonist for the prostatic smooth muscle, has little effect on the blood vessels and has been widely used in clinical practice. A combined treatment with levofloxacin and $\alpha_{1 \mathrm{~A}}$ adrenergic antagonists has been standard in clinical trials. However, there is concern about the interaction of the two drugs. Administered drugs are mainly metabolized through the liver and excreted by the kidney, which constitutes a site of blood vessel risk. The side effects to the liver and kidney should also be considered, particularly for older adults and those patients with hepatic or renal dysfunction.

In this study, to provide further experimental evidence for the validity, specificity and safety of the combination therapy, we developed a reproducible rat model of acute bacterial prostatitis (ABP). Through detection of the levofloxacin concentration by high performance liquid chromatography (HPLC) in the plasma, liver, kidney and prostate, we aimed to study the influence of tamsulosin on the pharmacokinetics of levofloxacin.

\section{MATERIALS AND METHODS}

Animals and bacteria

A total of 106 adult male Sprague-Dawley rats weighing 180-220 g were obtained from the Animal Experimental Centre of Chongqing

\footnotetext{
${ }^{1}$ Department of Urology, the First Affiliated Hospital, Chongqing Medical University, Chongqing 400016, China; ${ }^{2}$ Department of Clinical Pharmacology, the First Affiliated Hospital, Chongqing Medical University, Chongqing 400016, China and ${ }^{3}$ Department of Pathobiology, College of Basic Medicine, Chongqing Medical University, Chongqing 400016, China

* These authors contributed equally to this work.

Correspondence: Dr MZ Xiao (xmz.2004@163.com)
}

Received: 23 September 2012; Revised: 14 October 2012; Accepted: 6 November 2012; Published online: 28 January 2013 
Medical University. The rats were raised in a total of 22 cages at $20{ }^{\circ} \mathrm{C}-23{ }^{\circ} \mathrm{C}$ with a $12: 12$-hour light/dark cycle. All animal care and experimental procedures were performed in compliance with the Institutional Animal Care and Use Committee guidelines. The rats had free access to food and drink and were allowed to adapt to the new environment for a week before the experiment. Standard Escherichia coli (E. coli) strains (ATCC25922, kindly provided by Department of Infectious Disease, the First Affiliated Hospital, Chongqing Medical University, Chongqing, China) were stored at $-80{ }^{\circ} \mathrm{C}$ before being grown overnight in tryptic soy broth at $37{ }^{\circ} \mathrm{C}$ and used for inoculations. The bacterial cells were pelleted, washed three times in sterile phosphate-buffered saline and resuspended at a concentration of $10^{7}-10^{8}$ colony-forming units per $\mathrm{ml}$.

\section{Instruments and chromatographic conditions}

The HPLC system was an Agilent (Agilent Corporation, Santa Clara, CA, USA) 1100 series LC system equipped with a degasser (G1328A), an iso pump (G1310A) and a thermostat column oven (CTO10A), along with a UV detector (G1314A) that was used to inject $40 \mu \mathrm{l}$ of the processed samples onto a Phenomenex Luna C18 column $(4.6 \times 250 \mathrm{~mm}, 5.0 \mu \mathrm{m})$, maintained at $35{ }^{\circ} \mathrm{C} \pm 2{ }^{\circ} \mathrm{C}$. The isocratic mobile phase system, consisting of methanol $\left(0.008 \mathrm{~mol} \mathrm{l}^{-1}\right)$, phosphate buffer $\left(0.5 \mathrm{~mol} \mathrm{l}^{-1}\right)$ and four butadiene styrene-brominated ammonium $(25: 75: 4, \mathrm{v} / \mathrm{v} / \mathrm{v})$, was delivered at a flowrate of $1.2 \mathrm{ml}$ $\min ^{-1}$ through the column to elute the analytes. The eluate was monitored using the UV detector set at $290 \mathrm{~nm}$. The data were acquired and processed with the Agilent 1100 ChemStation software program (Version B.04.03).

\section{Standard solutions}

The primary standard stock of levofloxacin was prepared in $\mathrm{MeOH} /$ $\mathrm{H}_{2} \mathrm{O} 50 / 50(\mathrm{v} / \mathrm{v})$ at a concentration of $97.6 \mathrm{mg} \mathrm{l}^{-1}$, and the standard solution of ciprofloxacin (internal standard) was prepared in $\mathrm{MeOH} /$ $\mathrm{H}_{2} \mathrm{O} 50 / 50(\mathrm{v} / \mathrm{v})$ at a concentration of $33.6 \mathrm{mg} \mathrm{l}^{-1}$. The standard solution of levofloxacin was appropriately diluted to standard working solution for use in calibration and experiments and stored at $4{ }^{\circ} \mathrm{C}$ for 1 month.

\section{Bacterial prostatitis model}

Model rats of bacterial prostatitis described previously ${ }^{12,13}$ were employed in this study. Briefly, 106 male Sprague-Dawley rats, approximately 180-220 g each, were anaesthetized with $10 \%$ chloral hydrate $\left(3 \mathrm{ml} \mathrm{kg}^{-1}\right)$ and subjected to laparotomy to expose the ventral prostate. ABP was induced by the injection of $0.2 \mathrm{ml}$ of the $E$. coli suspension. The bacterial solution was injected with a $30-\mathrm{G}$ needle directly beneath the capsules of both ventral lobes. The peritoneum, abdominal muscles and skin were closed carefully. After the operation, rats had free access to food and drink. Some rats were selected randomly 5 days later to be killed to assess the intensity of the prostate infections.

\section{Experimental groups and treatments}

Ninety-six model rats with ABP were randomly divided into two groups: the experimental group (treated with both tamsulosin and levofloxacin, $n=48$ ) and the control group (treated with levofloxacin and solvents, $n=48$ ). The rats in the experimental group were administered Tamsulosin Hydrochloride Sustained Release Capsules (0.022 $\mathrm{mg} \mathrm{kg}^{-1}$, diluted in solvents, Trade name: Harnal, $0.2 \mathrm{mg}$ per capsules, Astellas, Shenyang, China) using orogastric tubes on the fourth day after $E$. coli injection, and once more $24 \mathrm{~h}$ after the initial administration; at the same time, the control group was administered the solvents. On the fifth day, rats in both the experimental and control groups were administered levofloxacin $\left(44 \mathrm{mg} \mathrm{kg}^{-1}\right.$, diluted in solvents, Trade name: Lailixin, $0.2 \mathrm{~g}$ per tablet, Xinchang, Zhejiang, China) using orogastric tubes $1 \mathrm{~h}$ after the two groups had been administered either tamsulosin or solvents. The remaining 10 rats were not treated.

\section{Sample collection and preparation}

Six rats from each group were euthanized to collect blood samples for plasma extraction and liver, kidney and prostate samples for tissue homogenates at the time points $0.125,0.25,0.5,1,2,4,8$ and $12 \mathrm{~h}$ after levofloxacin administration. The blood was centrifuged at $5000 \mathrm{~g}$ for 5 min to extract the plasma, which was stored at $-20{ }^{\circ} \mathrm{C}$. The liver, kidney and prostate tissues, free from the capsule, were dried with filter paper, weighed and then prepared into tissue homogenate with $2 \mathrm{ml}$ of normal saline and stored at $-20^{\circ} \mathrm{C}$. Blood samples for plasma extraction and liver, kidney and prostate samples for tissue homogenates were collected from the remaining 10 rats to establish the methodology and generate calibration curves.

\section{Sample pretreatment}

The levofloxacin was extracted from plasma and tissues using the protein precipitation method reported previously. ${ }^{14,15}$ Briefly, $500 \mu \mathrm{l}$ of each sample was fortified with $30 \mu \mathrm{l}$ of internal standard (ciprofloxacin, $33.6 \mathrm{mg} \mathrm{l}^{-1}$ ). Proteins were precipitated from the samples with $4 \mathrm{ml}$ of methylene chloride. After vortex mixing for $1 \mathrm{~min}$ and centrifugation ( $10 \mathrm{~min}, 3000 \mathrm{~g}$ ), the supernatant was transferred into a glass centrifuge tube for evaporation under nitrogen at $50{ }^{\circ} \mathrm{C}$ until it was dry (30 min). The dried residue was redissolved in $100 \mu \mathrm{l}$ of eluent (methanol $0.008 \mathrm{~mol} \mathrm{l}^{-1}$, phosphate buffer $0.5 \mathrm{moll}^{-1}$ and four butadiene styrene-brominated ammonium, $25: 75: 4$, v/v/v), and a 40- $\mu \mathrm{l}$ aliquot was injected into Phenomenex Luna C18 column.

\section{Method validation}

The method was validated in accordance with the Food and Drug Administration guidelines of the United States.

\section{Calibration curves}

The calibration curve was generated by plotting the ratio of the sums of the peak areas for levofloxacin to those for ciprofloxacin against the normal concentrations of the calibration standards. The final concentrations of the calibration standards obtained for plotting the calibration curve were $15.616,7.808,3.904,1.952,0.976,0.488,0.244$ and $0.049 \mathrm{mg} \mathrm{l}^{-1}$. The results were fitted to linear regression analysis using $1 / X^{2}$ as the weighting factor. The calibration curves were required to have a correlation coefficient $(r)$ of 0.999 or better. The acceptance criterion for each back-calculated standard concentration was $\pm 15 \%$ deviation from the nominal value, except at the lower limit of quantitation (LLOQ), which was set at $\pm 20 \%$.

\section{Precision, accuracy and recovery}

The intraday assay precision and accuracy were estimated by analysing five replicates on the same day at three different quality control (QC) levels, i.e., 9.76, 2.44 and $0.98 \mathrm{mg} \mathrm{l}^{-1}$ for plasma; 7.808, 1.952 and $0.488 \mathrm{mg} \mathrm{l}^{-1}$ for hepatic samples; 3.904, 0.976 and $0.244 \mathrm{mg} \mathrm{l}^{-1}$ for kidney samples; and 2.928, 0.976 and $0.195 \mathrm{mg} \mathrm{l}^{-1}$ for prostatic samples. To determine interday precision, the QC samples listed above were analysed in duplicate for 5 days. The intra- and interassay precision was determined by analysing the three QC sample levels from 
different samples on three different runs. The criteria for acceptability of the data included accuracy of within $\pm 15 \%$ standard deviation (s.d.) from the normal values and precision of within $\pm 15 \%$ relative standard deviation (RSD), except for LLOQ, for which a $\pm 20 \%$ accuracy and precision should not be exceeded. The recovery of an analyte extracted from the plasma and other samples was determined by comparing the response of the analytes extracted from replicate QC samples $(n=5)$ with the response of the analytes from aqueous standard samples at equivalent concentrations. As above, the recovery of levofloxacin in different samples was determined at QC low (L), medium (M) and high $(\mathrm{H})$ concentrations.

\section{Stability experiments}

The stability was estimated by analysing three replicates at two different QC levels, i.e., 9.76 and $0.98 \mathrm{mg} \mathrm{l}^{-1}$ for plasma, 7.808 and $0.488 \mathrm{mg} \mathrm{l}^{-1}$ for hepatic samples, 3.904 and $0.244 \mathrm{mg} \mathrm{l}^{-1}$ for kidney samples and 2.928 and $0.195 \mathrm{mg} \mathrm{l}^{-1}$ for prostatic samples. The shortterm stability of the levofloxacin in the plasma and other samples was studied under the following two experimental conditions: after storage in a centrifuge tube $\left(22^{\circ} \mathrm{C} \pm 3{ }^{\circ} \mathrm{C}\right)$ for 12 and $24 \mathrm{~h}$ and after five freezethaw (FT) cycles within 30 days. The stability of the samples in the centrifuge tubes at different times was tested according to the following procedure: a total of nine extracts of each QC sample were prepared, of which three were analysed immediately, three were analysed $12 \mathrm{~h}$ later and the last three were analysed $24 \mathrm{~h}$ later. Stability was then determined by comparing the concentration of the first three analysed samples with those of the second three samples and the last three samples through statistical data analysis. Furthermore, FT stability was determined using the commonly accepted procedure. After three FT cycles, the samples were compared with regularly analysed samples with the same amount of analyte.

\section{Statistical analysis}

The pharmacokinetic parameters of the two groups were calculated with the 3p97 software program (purchased from the Association of Pharmacology and Mathematics, Beijing, China). Quantitative data were analysed by $t$-tests using SPSS (Statistical Package for the Social Sciences) 17.0 , with $P<0.05$ considered statistically significant.

\section{RESULTS}

\section{Pathological study}

In normal prostatic glands, the alveoli were regular with a thin interstitium. Glandular epithelial cells were cubic or columnar and well arranged. There were stained secretions in the glandular cavity, but no oedema or infiltration by inflammatory cells was found (Figure 1a). Acute inflammatory changes in the prostatic tissues were noted 5 days after E. coli injection. We observed some inflammatory cells in the prostatic glandular cavity, and the glandular structure was intact. Interstitial oedema and infiltration by inflammatory cells were obvious. Interstitial vascular dilatation and congestion were also present (Figure 1b).

\section{Chromatographic characteristics}

Under the chromatographic conditions described, levofloxacin peaks were well resolved in the plasma and tissue samples. It was found that the mean retention time of levofloxacin was approximately $5 \mathrm{~min}$ in the plasma and tissue samples without the interference of endogenous substances in each sample. The chromatograms of levofloxacin in the plasma and tissue samples are shown in Figure 2.
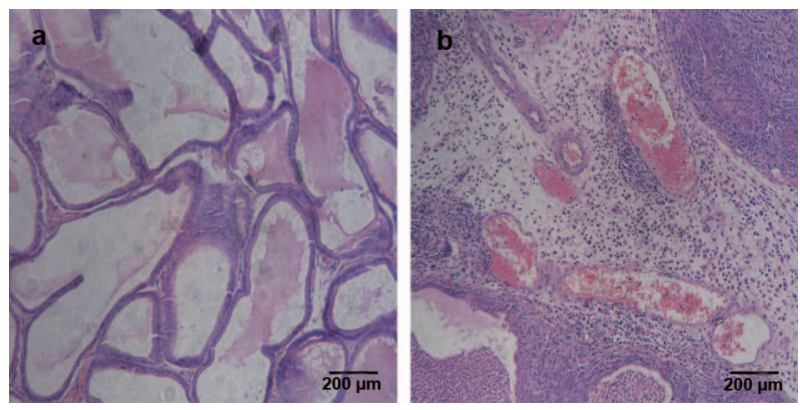

Figure 1 Pathology of prostatic tissue sections. Light microscopy shows prostatic tissue sections. (a) In normal prostatic gland, alveoli were regular with thin interstitium. Glandularepithelial cellswere cubic or columnar and well arranged. Therewerestained secretions in glandular cavity but no oedema or infiltration by inflammatory cells. Hematoxylin and eosin (H\&E) stained, scale bar $=200 \mu \mathrm{m}$. (b) Prostatic tissue acute inflammatory changes 5 days after E. coliwas injected. Some inflammatory cellswere in prostatic glandular cavity but glandular cavity and epithelium were structurally intact. Interstitial oedema and infiltration by lots of inflammatory cells, as well as interstitial vascular dilatation and congestion were observed. H\&E stained, scale bar $=200 \mu \mathrm{m}$.

\section{Calibration curves}

Calibration curves for the plasma and tissue samples were constructed using eight calibration standards (i.e., $0.049-15.616 \mathrm{mg} \mathrm{l}^{-1}$ ). The calibration standard curves had reliable reproducibility over the standard concentrations across the calibration range. The calibration curves were prepared by determining the best fit of peak-area ratios (peak area levofloxacin/peak area ciprofloxacin) vs. concentration and were fitted to $y=m x+c$ using the weighing factor $\left(1 / X^{2}\right)$. The regression equations for the plasma and tissue samples were $y=0.8679 x+0.0137 \quad(r=0.9992)$ for the plasma, $y=1.4405 x-0.2837 \quad(r=0.9995)$ for the liver, $y=1.2313 x+0.1348(r=0.9999)$ for the kidney and $y=1.2207 x+0.0316$ $(r=0.9993)$ for the prostate, where $y$ is the peak-area of the levofloxacin to the internal standard (ciprofloxacin), $x$ is the concentration in the plasma or tissue sample $\left(\mathrm{mg} \mathrm{l}^{-1}\right)$ and $r$ is the coefficient of correlation. Statistical analysis confirmed the linearity of this method. The LLOQ was established at $0.0488 \mathrm{mg} \mathrm{l}^{-1}$ in the plasma and tissue samples, and it was sensitive enough for our pharmacokinetic studies.

\section{Precision, accuracy and recovery}

Inter- and intraday precision (both defined by RSD \%) and accuracy were evaluated using QC samples. The accuracy and precision data for intra- and interday samples are presented in Table 1 . The assay values for both comparisons (intra- and interday) were found to be within the accepted variable limits. Furthermore, the extraction mean recovery in plasma at HQC, MQC and LQC was $99.61 \pm 2.93 \%$ $(\mathrm{RSD}=2.94 \%), 101.14 \pm 2.52 \%(\mathrm{RSD}=2.49 \%)$, and $101.13 \pm 4.06 \%$ $(\mathrm{RSD}=4.01 \%)$, respectively. The extraction mean recovery in hepatic tissues at HQC, MQC and LQC was $98.60 \pm 3.64 \%(\mathrm{RSD}=3.69 \%)$, $95.81 \pm 3.06 \%(\mathrm{RSD}=3.19 \%)$, and $100.56 \pm 2.57 \% \quad(\mathrm{RSD}=2.56 \%)$, respectively. The extraction mean recovery in kidney tissues at HQC, MQC and LQC was 97.89 $2.85 \%(\mathrm{RSD}=2.91 \%), 100.17 \pm$ $3.80 \%(\mathrm{RSD}=3.79 \%)$, and $96.71 \pm 3.68 \%(\mathrm{RSD}=3.80 \%)$, respectively. Finally, the extraction mean recovery in prostatic tissues at HQC, MQC and LQC was $91.62 \pm 1.54 \%(\mathrm{RSD}=1.68 \%), 95.18 \pm 1.79 \%$ $(\mathrm{RSD}=1.88 \%)$, and $96.11 \pm 2.66 \%(\mathrm{RSD}=2.77 \%)$, respectively.

\section{Stability}

No obvious difference in the measured concentration was observed during the 0,12 and $24 \mathrm{~h}$ periods. Consequently, the extracted samples were left in the centrifuge tube $\left(22^{\circ} \mathrm{C} \pm 3{ }^{\circ} \mathrm{C}\right)$ for 12 or $24 \mathrm{~h}$ prior to 

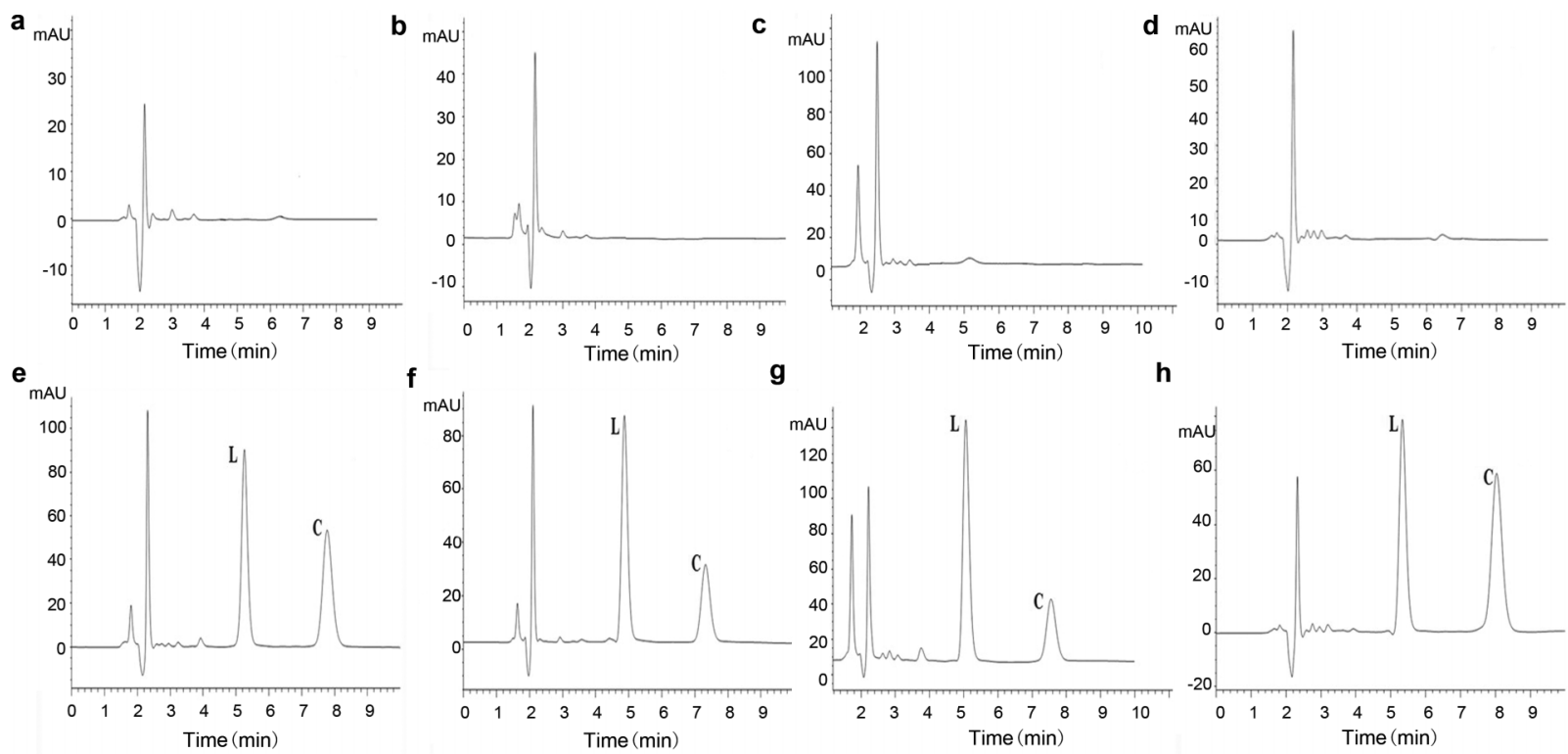

Figure 2 Chromatograms of levofloxacin and ciprofloxacin in plasma, hepatic, renal and prostatic samples. L: peak of levofloxacin; C: peak of ciprofloxacin; (a)-(d) show chromatogram of blank plasma, hepatic, renal and prostatic samples, respectively; (e)-(h) show chromatogram of plasma, hepatic, renal and prostatic samples $1 \mathrm{~h}$ after levofloxacin administration, respectively.

analysis. In the five FT (ambient temperature $-20^{\circ} \mathrm{C}$ ) cycles within 30 days, the levofloxacin was stable in plasma and the tissue samples at the low QC and the high QC concentration levels, indicating no significant substance loss during repeated thawing and freezing (Table 2).

\section{Concentration of levofloxacin}

The concentrations of levofloxacin in plasma and the liver, kidney and prostate tissues at different time points after levofloxacin administration were calculated based on the calibration curves for each tissue (Table 3), and the mean concentration-time curves of levofloxacin in different samples are shown in Figure 3.

\section{Pharmacokinetic parameters}

The pharmacokinetic parameters of levofloxacin in the plasma and tissue samples were calculated by inputting the data on the drug concentration-time into the $3 \mathrm{p} 97$ software program. The results showed that the concentration-time curves of levofloxacin in the plasma, liver and kidney samples of the two groups fit the two-compartment model, and in the prostate, the concentration-time curves of both the experimental and control groups fit the one-compartment model. The pharmacokinetic parameters of levofloxacin in the plasma and tissue samples are shown in Tables $\mathbf{4}$ and $\mathbf{5}$.

\section{DISCUSSION}

Prostatitis represents a combination of infectious diseases (acute and chronic bacterial prostatitis), chronic pelvic pain syndrome and asymptomatic inflammation. The National Institute of Health classification has been accepted internationally and includes four syndromes that occur as a result of various causes of the inflammation or swelling of the prostate gland. ${ }^{16}$ Most cases of ABP are caused by Gram-negative bacteria, of which E. coli is the most commonly identified organism. ${ }^{17}$ ABP onset occurs urgently, generally has obvious

Table 1 Inter- and intraday precisions (RSD \%) and accuracies of levofloxacin (mean \pm s.d., $n=5$ )

\begin{tabular}{|c|c|c|c|c|c|c|c|}
\hline \multirow{2}{*}{ Samples } & \multirow{2}{*}{$\begin{array}{c}\text { Added concentration } \\
\left(m g \Gamma^{-1}\right)\end{array}$} & \multicolumn{3}{|c|}{ Intraday assays } & \multicolumn{3}{|c|}{ Interday assays } \\
\hline & & $\begin{array}{l}\text { Measured concentration } \\
\qquad\left(m g l^{-1}\right)\end{array}$ & $R S D(\%)$ & Accuracy (\%) & $\begin{array}{l}\text { Measured concentration } \\
\qquad\left(m g I^{-1}\right)\end{array}$ & $R S D(\%)$ & Accuracy (\%) \\
\hline \multirow[t]{3}{*}{ Plasma } & 9.76 & $9.72 \pm 0.23$ & 2.37 & 99.5 & $9.88 \pm 0.27$ & 2.73 & 101 \\
\hline & 2.44 & $2.56 \pm 0.21$ & 8.20 & 105 & $2.57 \pm 0.17$ & 6.61 & 105 \\
\hline & 0.976 & $0.992 \pm 0.05$ & 5.04 & 102 & $0.991 \pm 0.03$ & 3.03 & 102 \\
\hline \multirow[t]{3}{*}{ Liver } & 7.808 & $7.786 \pm 0.32$ & 4.11 & 99.7 & $7.992 \pm 0.27$ & 3.38 & 102 \\
\hline & 1.952 & $1.956 \pm 0.09$ & 4.60 & 100 & $1.997 \pm 0.10$ & 5.01 & 102 \\
\hline & 0.488 & $0.493 \pm 0.02$ & 4.06 & 101 & $0.493 \pm 0.03$ & 6.08 & 101 \\
\hline \multirow[t]{3}{*}{ Kidney } & 3.904 & $3.914 \pm 0.21$ & 5.36 & 100 & $3.941 \pm 0.29$ & 7.36 & 101 \\
\hline & 0.978 & $0.978 \pm 0.03$ & 3.07 & 100 & $0.993 \pm 0.05$ & 5.04 & 102 \\
\hline & 0.244 & $0.254 \pm 0.02$ & 7.87 & 104 & $0.255 \pm 0.02$ & 7.84 & 105 \\
\hline \multirow[t]{3}{*}{ Prostate } & 2.928 & $2.948 \pm 0.13$ & 4.41 & 101 & $2.991 \pm 0.19$ & 6.35 & 102 \\
\hline & 0.976 & $0.982 \pm 0.06$ & 6.12 & 100 & $0.984 \pm 0.05$ & 5.10 & 100 \\
\hline & 0.195 & $0.195 \pm 0.02$ & 9.24 & 100 & $0.196 \pm 0.02$ & 9.72 & 100 \\
\hline
\end{tabular}

Abbreviation: $\mathrm{RSD}$, relative standard deviation. 
Table 2 The stability of levofloxacin in different samples 12 and $24 \mathrm{~h}$ after extraction and five freeze $\left(-20^{\circ} \mathrm{C}\right)$-thaw (ambient temperature) cycles within 30 days

\begin{tabular}{|c|c|c|c|c|c|}
\hline \multirow{2}{*}{ Samples } & \multirow{2}{*}{$\begin{array}{l}\text { Added concentration } \\
\left(m g I^{-1}\right)\end{array}$} & \multicolumn{2}{|c|}{ Different time interval } & \multicolumn{2}{|c|}{ Five freeze-thaw cycles } \\
\hline & & $\begin{array}{l}\text { Measured concentration } \\
\qquad\left(m g I^{-1}\right)\end{array}$ & $R S D(\%)$ & $\begin{array}{l}\text { Measured concentration } \\
\qquad\left(m g \Gamma^{-1}\right)\end{array}$ & $R S D(\%)$ \\
\hline \multirow[t]{2}{*}{ Plasma } & 9.76 & $9.64 \pm 0.79$ & 8.20 & $9.93 \pm 0.67$ & 6.75 \\
\hline & 0.976 & $0.978 \pm 0.08$ & 8.18 & $0.992 \pm 0.07$ & 7.06 \\
\hline \multirow[t]{2}{*}{ Liver } & 7.808 & $7.994 \pm 0.58$ & 7.26 & $7.622 \pm 0.64$ & 8.40 \\
\hline & 0.488 & $0.508 \pm 0.03$ & 5.91 & $0.505 \pm 0.03$ & 5.94 \\
\hline \multirow[t]{2}{*}{ Kidney } & 3.904 & $3.953 \pm 0.24$ & 6.07 & $4.014 \pm 0.23$ & 5.74 \\
\hline & 0.244 & $0.242 \pm 0.02$ & 8.26 & $0.241 \pm 0.02$ & 8.30 \\
\hline \multirow[t]{2}{*}{ Prostate } & 2.928 & $2.825 \pm 0.14$ & 4.96 & $2.948 \pm 0.24$ & 8.14 \\
\hline & 0.1952 & $0.1877 \pm 0.01$ & 7.45 & $0.2019 \pm 0.02$ & 8.92 \\
\hline
\end{tabular}

clinical symptoms and accounts for a significantly greater number of men with prostatitis who were diagnosed with benign prostate hyperplasia than controls. ${ }^{8}$ Inflammation, which promotes prostate growth, may contribute to a predisposition for bladder and prostate infection by causing incomplete bladder emptying. The proliferation of the glandular mass (prostatic ducts and acini) could theoretically result in an increase in the intraprostatic ductal reflux and intraprostatic pressure. ${ }^{8}$ These conditions can also increase the opportunity for a bacterial infection of the prostate and reduce the chance of a cure. ${ }^{18}$ If patients with ABP are not treated in a timely and thorough manner, the disease may progress or recur, protract its course and become chronic prostatitis. ${ }^{8,19}$

Levofloxacin belongs to the fluoroquinolone family, which has a broad antibacterial spectrum against both Gram-positive and Gramnegative bacteria, as well as against atypical pathogens. Thus, levofloxacin has favourable pharmacokinetic properties for controlling prostatitis, including preferential accumulation in the prostatic tissue and fluids. Therefore, levofloxacin has been in wide clinical use and is considered the drug of choice for antimicrobial treatment of acute and chronic bacterial prostatitis. ${ }^{7,20}$ However, the long-term and irregular use of levofloxacin for the treatment of prostatitis can lead to the selective growth of levofloxacin-resistant pathogens. Therefore, its regular use in combination with other drugs for prostatitis is a preferred choice. In the prostatic fibromuscular stroma, capsule and bladder neck, many $\alpha$-adrenergic receptors, the majority of which are $\alpha_{1 \mathrm{~A}}$ receptors, exist. $\alpha_{1 \mathrm{~A}}$ adrenergic antagonists can lead to smooth muscle relaxation in the prostate and bladder neck and the relief of prostate capsule retention, which in turn can reduce internal prostate pressure, increase the urine flowrate and decrease urine reflux. All these effects have the potential to relieve prostatitis symptoms and improve quality of life. The combination of levofloxacin and $\alpha_{1 \mathrm{~A}}$ adrenergic antagonists may have a synergetic effect on the treatment of $\mathrm{ABP}$.

In this study, we applied HPLC to analyse levofloxacin pharmacokinetics in model rats with ABP. The HPLC method was developed and validated for the detection of levofloxacin in human or animal plasma and tissues ${ }^{14,15}$, and we have validated the reliability and suitability of this method for our study. We explored the influence of tamsulosin on the pharmacokinetics of levofloxacin in plasma, liver, kidney and prostate tissues by reconstructing model rats with ABP and detecting the concentration of levofloxacin at different time points in these tissues using HPLC. The results indicated that in combined treatment with levofloxacin and tamsulosin for ABP, tamsulosin has no obvious influence on the major pharmacokinetic parameters of levofloxacin, including the halftime $\left(t_{1 / 2}\right)$, time to peak $\left(t_{\text {peak }}\right)$, clearance rates $(\mathrm{CL})$, maximum concentration $\left(C_{\max }\right)$ and area under the curves $\left(\mathrm{AUC}_{0 \sim 12}\right)$ in plasma, liver and kidney samples. However, in prostate samples, tamsulosin obviously increased the $C_{\max }$, prolonged the $t_{1 / 2}$ and decreased the CL of levofloxacin. All of these results suggest that tamsulosin, as a new-generation highly selective $\alpha_{1 \mathrm{~A}}$ blocker, may have little influence on the smooth muscle and blood vessels in the liver and kidney but may be able to selectively relax the smooth muscle and ease the pressure of vessels in the prostate, increasing blood flow and the concentration of levofloxacin locally. Moreover, a previous study ${ }^{21}$ has shown that in patients, the amount of tamsulosin freely available in the prostate is much higher than that available in plasma, which may contribute to the relative 'uroselectivity' of tamsulosin. This study also indicates that when levofloxacin is used together with tamsulosin for bacterial prostatitis, tamsulosin has no influence on the levofloxacin load in the liver and kidney. As a treatment for bacterial prostatitis, the combination of levofloxacin and tamsulosin demonstrated favourable specificity and safety.

Table 3 The concentration of levofloxacin at different time points in plasma ( $\mathrm{mg} \mathrm{I}^{-1}$, mean \pm s.d., $n=6$ ) and other tissues of liver, kidney and prostate (mg kg ${ }^{-1}$, mean \pm s.d., $\left.n=6\right)$ after administration of levofloxacin $\left(44 \mathrm{mg} \mathrm{kg}^{-1}\right)$

\begin{tabular}{|c|c|c|c|c|c|c|c|c|c|}
\hline \multirow{2}{*}{\multicolumn{2}{|c|}{ Samples groups }} & \multicolumn{7}{|c|}{ Time (h) } & \multirow[b]{2}{*}{12} \\
\hline & & 0.125 & 0.25 & 0.5 & 1 & 2 & 4 & 8 & \\
\hline \multirow[t]{2}{*}{ Plasma } & Control & $6.56 \pm 0.74$ & $11.95 \pm 2.08$ & $9.48 \pm 1.26$ & $7.01 \pm 0.91$ & $5.14 \pm 0.67$ & $2.77 \pm 0.39$ & $1.24 \pm 0.13$ & $0.37 \pm 0.12$ \\
\hline & Experimental & $7.72 \pm 1.43$ & $12.93 \pm 1.14$ & $9.03 \pm 1.24$ & $7.13 \pm 0.69$ & $5.55 \pm 0.30$ & $2.99 \pm 0.57$ & $1.93 \pm 0.56$ & $0.63 \pm 0.11$ \\
\hline \multirow[t]{2}{*}{ Liver } & Control & $9.04 \pm 1.19$ & $19.23 \pm 3.85$ & $11.25 \pm 1.84$ & $8.12 \pm 0.61$ & $6.02 \pm 0.43$ & $3.68 \pm 0.49$ & $2.01 \pm 0.07$ & $1.25 \pm 0.37$ \\
\hline & Experimental & $9.16 \pm 0.28$ & $20.33 \pm 1.77$ & $10.83 \pm 1.36$ & $7.77 \pm 1.21$ & $5.49 \pm 0.82$ & $3.40 \pm 0.49$ & $1.87 \pm 0.21$ & $1.27 \pm 0.29$ \\
\hline \multirow[t]{2}{*}{ Kidney } & Control & $5.79 \pm 0.82$ & $13.85 \pm 3.52$ & $9.51 \pm 2.02$ & $8.20 \pm 1.27$ & $7.02 \pm 0.95$ & $3.33 \pm 0.90$ & $1.42 \pm 0.28$ & $0.38 \pm 0.19$ \\
\hline & Experimental & $6.11 \pm 1.32$ & $11.63 \pm 1.66$ & $13.79 \pm 2.29$ & $9.64 \pm 1.85$ & $6.95 \pm 0.72$ & $2.85 \pm 0.34$ & $1.21 \pm 0.16$ & $0.40 \pm 0.22$ \\
\hline \multirow[t]{2}{*}{ Prostate } & Control & $1.22 \pm 0.45$ & $2.19 \pm 0.42$ & $5.06 \pm 0.30$ & $4.12 \pm 0.76$ & $3.23 \pm 0.48$ & $2.09 \pm 0.62$ & $1.28 \pm 0.25$ & $0.47 \pm 0.17$ \\
\hline & Experimental & $1.72 \pm 0.28$ & $2.74 \pm 0.52$ & $5.73 \pm 0.48$ & $8.68 \pm 0.53$ & $6.58 \pm 0.49$ & $3.60 \pm 0.51$ & $2.14 \pm 0.30$ & $1.64 \pm 0.18$ \\
\hline
\end{tabular}


a

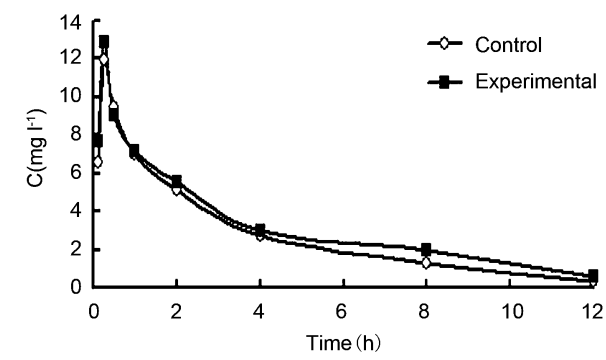

c

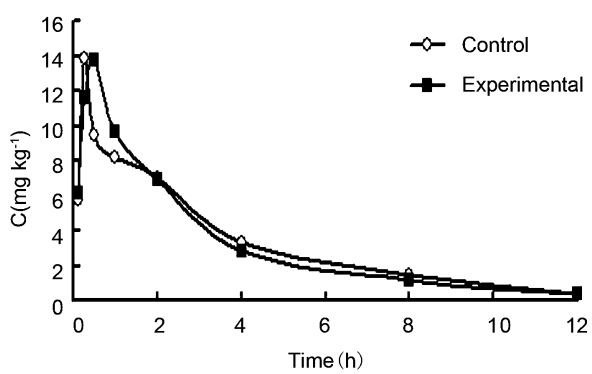

b

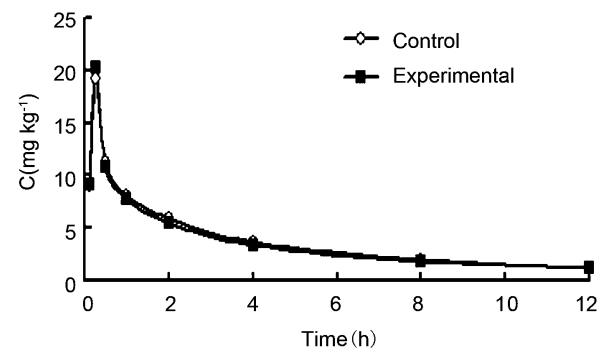

d

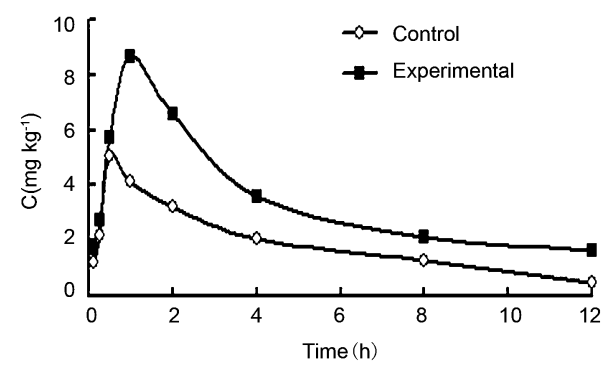

Figure 3 The mean concentration-time curves of levofloxacin in rats' plasma (a), liver (b), kidney (c) and prostate (d) after administration of levofloxacin (44 mg kg ${ }^{-1}$ ).

We were able to obtain adequate evidence from a rat model in support of the favourable effect of the combined treatment of prostatitis with levofloxacin and tamsulosin. Two potential explanations for this effect exist. First, by blocking the $\alpha_{1 \mathrm{~A}}$ adrenergic receptor in the prostate, tamsulosin might reduce urethral resistance and ease functional urethral obstruction through relaxation of the smooth muscle in the prostate and bladder neck, consequently improving patient scores for pain, urinary symptoms and

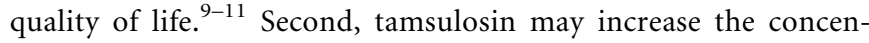
tration and prolong the duration of the antibacterial activity of levofloxacin in the prostate, thereby improving the effect of levofloxacin on the pathogenic microorganism. Alternatively, both of these factors could contribute to the favourable effects that were observed.

In this experiment, the results indicated that tamsulosin has a pronounced effect on the pharmacokinetics of levofloxacin in the prostate of model rats with ABP. In view of the pharmacological action of tamsulosin, we predicted that tamsulosin could also potentiate the

Table 4 Pharmacokinetic parameters of levofloxacin in plasma (mean \pm s.d., $n=6$ )

\begin{tabular}{lrr}
\hline $\begin{array}{l}\text { Pharmacokinetic } \\
\text { parameters }\end{array}$ & Experimental group & Control group \\
\hline$t_{1 / 2}(\mathrm{~h})$ & $3.24 \pm 0.64^{*}$ & $3.05 \pm 0.97$ \\
$t_{\text {peak }}(\mathrm{h})$ & $0.21 \pm 0.04^{*}$ & $0.22 \pm 0.04$ \\
$\mathrm{CL}\left(\mathrm{mg} \mathrm{h}^{-1}\right)$ & $1.18 \pm 0.09^{*}$ & $1.32 \pm 0.13$ \\
$C_{\max }\left(\mathrm{mg} \mathrm{I}^{-1}\right)$ & $14.72 \pm 1.89^{*}$ & $12.99 \pm 2.42$ \\
$\mathrm{A \cup C} \mathrm{C}_{0 \sim 12}\left(\mathrm{mg} \mathrm{h} \mathrm{I}^{-1}\right)$ & $38.38 \pm 4.19^{*}$ & $33.61 \pm 2.48$ \\
\hline
\end{tabular}

Abbreviations: $\mathrm{AUC}$, area under the curve; $\mathrm{CL}$, clearance rate; $C_{\max }$, maximum concentration; $t_{1 / 2}$, halftime; $t_{\text {peak }}$, time to peak.

$* P>0.05$ compared with control group. local prostate effect of other antibiotics. As all the pharmacokinetic data in this study were obtained from rat models with ABP, there are potential limitations for extending these results to clinical practice. First, the rat model of ABP was induced by an injection of an E. coli suspension directly into the prostate, which is a different infection route from that of human bacterial prostatitis. Second, there is a vast difference in the prostatic structure and inflammatory reactions of human and rats. Therefore, the data from our animal model should be further evaluated for applicability to human prostatitis. Finally, the acute inflammatory stage is extremely different from the chronic inflammatory stage; thus, the pharmacokinetic data of this study may not apply to models with chronic prostatitis. Further investigations are required to generalize and apply our research findings to clinical use in humans.

In summary, this study explored the impact of tamsulosin on the pharmacokinetics of levofloxacin in the plasma and several tissues of model rats with ABP; it also provided additional experimental evidence for the validity, specificity and safety of this combination treatment for $\mathrm{ABP}$, affirming the theoretical basis for its clinical use. However, in this study, ABP was only explored in a rat model. Prostatitis is composed of many different classifications, causes and complicated pathological mechanisms. Therefore, further studies are required to clarify whether the findings of this study can be applied to different pathological models (such as hormone-associated, autoimmune, spontaneous and viral causes) and human disease.

\section{AUTHOR CONTRIBUTIONS}

GDQ performed the animal and HPLC method studies, analysed data and wrote the paper; MZX conceived of the study, and participated in its design and coordination and helped to draft the manuscript; YDZ and JY participated in the design of the study and analysed data; $\mathrm{HXH}$ performed the HPLC method studies; YZ and YH performed the 
Table 5 Pharmacokinetic parameters of levofloxacin in liver, kidney and prostate (mean \pm s.d., $n=6$ )

\begin{tabular}{|c|c|c|c|c|c|c|}
\hline \multirow{2}{*}{ Pharmacokinetic parameters } & \multicolumn{2}{|c|}{ Liver sample } & \multicolumn{2}{|c|}{ Kidney sample } & \multicolumn{2}{|c|}{ Prostate sample } \\
\hline & Experimental group & Control group & Experimental group & Control group & Experimental group & Control group \\
\hline$t_{1 / 2}(\mathrm{~h})$ & $4.54 \pm 1.04$ & $3.93 \pm 0.66$ & $2.63 \pm 0.66$ & $2.68 \pm 0.59$ & $4.78 \pm 0.75^{\#}$ & $3.64 \pm 0.88$ \\
\hline $\mathrm{CL}\left(\mathrm{mg} \mathrm{h}^{-1}\right)$ & $0.85 \pm 0.17$ & $0.88 \pm 0.07$ & $1.11 \pm 0.16$ & $1.09 \pm 0.12$ & $0.88 \pm 0.05 *$ & $1.88 \pm 0.23$ \\
\hline$C_{\max }\left(\mathrm{mg} \mathrm{kg}^{-1}\right)$ & $23.39 \pm 8.02$ & $23.16 \pm 7.27$ & $13.25 \pm 2.27$ & $13.16 \pm 2.92$ & $6.16 \pm 0.57^{*}$ & $3.91 \pm 0.62$ \\
\hline $\left.\mathrm{AUC}_{0 \sim 12}(\mathrm{mg} \mathrm{h} \mathrm{kg})^{-1}\right)$ & $43.29 \pm 2.18$ & $45.41 \pm 2.04$ & $40.20 \pm 3.23$ & $39.74 \pm 4.63$ & $41.91 \pm 1.01 *$ & $22.70 \pm 3.08$ \\
\hline
\end{tabular}

Abbreviations: AUC, area under the curve; $\mathrm{CL}$, clearance rate; $C_{\max }$, maximum concentration; $t_{1 / 2}$, halftime; $t_{\text {peak }}$, time to peak.

${ }^{\#} P<0.05, * P<0.01$ compared with the corresponding control group.

animal studies. All authors discussed the results and implications and commented on the manuscript at all stages.

\section{COMPETING FINANCIAL INTERESTS}

The authors declare that they have no competing financial interests.

1 Liang CZ, Li HJ, Wang ZP, Xing JP, Hu WL et al. Treatment of chronic prostatitis in Chinese men. Asian J Androl 2009; 11: 153-6.

2 Kreiger JN, Lee SW, Jeon J, Cheah PY, Liong ML et al. Epidemiology of prostatitis. Int J Antimicrob Agents 2008; 31 (Suppl 1): S85-90.

3 Tripp DA, Nickel JC, Landis JR, Wang YL, Knauss JS et al. Predictor of quality of life and pain in chronic prostatitis/chronic pelvic pain syndrome: finding from the National Institutes of Health Chronic Prostatitis cohort Study. BJU Int 2004; 9: 1279-82.

4 Nickel JC, Downey J, Ardern D, Clark J, Nickel K. Failure of a monotherapy strategy for difficult chronic prostatitis/chronic pelvic pain syndrome. J Urol 2004; 2: 551-4.

5 Lipsky BA, Byren I, Hoey CT. Treatment of bacterial prostatitis. Clin Infect Dis 2010; 50: 1641-52.

6 Wagenlehner FM, Weidner W, Naber KG. Therapy for prostatitis, with emphasis on bacterial prostatitis. Expert Opin Pharmacother 2007; 11: 1667-74.

7 Schiller DS, Parikh A. Identification, pharmacologic considerations, and management of prostatitis. Am J Geriatr Pharmacother 2011; 1: 37-48.

8 Yoon $\mathrm{BI}, \mathrm{Kim} \mathrm{S}$, Han DS, Ha US, Lee SJ et al. Acute bacterial prostatitis: how to prevent and manage chronic infection? J Infect Chemother 2012; 18: 444-50.

9 Anothaisintawee T, Attia J, Nickel JC, Thammakraisorn S, Numthavaj P. Management of chronic prostatitis/chronic pelvic pain syndrome: a systematic review and network meta-analysis. JAMA 2011; 1: 78-86.

10 Ye ZQ, Lan RZ, Yang WM, Yao LF, Yu X. Tamsulosin treatment of chronic non-bacterial prostatitis. J Int Med Res 2008; 2: 244-52.
11 Thakkinstian A, Attia J, Anothaisintawee T, Nickel JC. $\alpha$-blockers, antibiotics and antiinflammatories have a role in the management of chronic prostatitis/chronic pelvic pain syndrome. BJU Int 2012; 110: 1014-22.

12 Elkahwaji JE, Ott CJ, Janda LM, Hopkins WJ. Mouse model for acute bacterial prostatitis in genetically distinct inbred strains. Urology 2005; 4: 883-7.

13 Quintar AA, Roth FD, de Paul AL, Aoki A, Maldonado CA. Toll-like receptor 4 in rat prostate: modulation by testosterone and acute bacterial infection in epithelial and stromal cell. Biol Reprod 2006; 5: 664-72.

14 de Smet J, Boussery K, Colpaert K, de Sutter P, Decruyenaere J. Pharmacokinetics of fluoroquinolones in critical care patients: a bio-analytical HPLC method for the simultaneous quantification of ofloxacin, ciprofloxacin and moxifloxacin in human plasma. J Chromatogr B Analyt Technol Biomed Life Sci 2009; 877: 961-7.

15 Srinivas N, Narasu L, Shankar BP, Mullangi R. Development and validation of a HPLC method for simultaneous quantitation of gatifloxacin, sparfloxacin and moxifloxacin using levofloxacin as internal standard in human plasma: application to a clinical pharmacokinetic study. Biomed Chromatogr 2008; 11: 1288-95.

16 Krieger JN, Nyberg LJ, Nickel JC. NIH consensus definition and classification of prostatitis. JAMA 1999; 3: 236-7.

17 Etienne M, Chavanet $\mathrm{P}$, Sibert L, Michel F, Levesque $\mathrm{H}$ et al. Acute bacterial prostatitis: heterogeneity in diagnostic criteria and management. Retrospective multicentric analysis of 371 patients diagnosed with acute prostatitis. BMC Infect Dis 2008; 8: 12.

18 Lee CB, Ha US, Yim SH, Lee HR, Sohn DW et al. Does finasteride have a preventive effect on chronic bacterial prostatitis? Pilot study using an animal model. Urol Int 2011; 2: 204-9.

19 Ha US, Kim ME, Kim CS, Shim BS, Han CH et al. Acute bacterial prostatitis in Korea: clinical outcome, including symptoms, management, microbiology and course of disease. Int J Antimicrob Agents 2008; 31 (Suppl 1): S96-101.

20 Naber KG. Management of bacterial prostatitis: what's new? BJU Int 2008; 3: 7-10.

21 Korstanje C, Krauwinkel W, van Doesum-Wolters FL. Tamsulosin shows a higher unbound drug fraction in human prostate than in plasma: a basis for uroselectivity? Br J Clin Pharmacol 2011; 72: 218-25. 